\title{
Land subsidence risk assessment and protection in mined-out regions
}

\author{
A. Zhao ${ }^{1,2}$ and A. Tang ${ }^{2,1}$ \\ ${ }^{1}$ School of Civil Engineering, Harbin Institute of Technology, Harbin, China \\ ${ }^{2}$ School of Civil Engineering, Heilongjiang University, Harbin, China \\ Correspondence to: A. Tang (tangap@ hit.edu.cn) \\ Published: 12 November 2015
}

\begin{abstract}
Land subsidence due to underground mining is an important hazard that causes large damages and threatens to social and economic activities. The China government has started a national project to estimate the risk of land subsidence in the main coal production provinces, such as Heilongjiang, Anhui and Shanxi Provinces. Herein, the investigation methods for land subsidence identification were reported, some types of land settlement are summarized, and some successful engineering measures to mitigate the subsidence are discussed. A Geographical Information System (GIS) for land subsidence risk assessment is developed and is based on site investigations and numerrical simulation of the subsidence process. In this system, maps of mining intensity and risk ranks are developed.
\end{abstract}

\section{Introduction}

In China, land subsidence in mined-out regions is an important hazard for sustainable economic and social development, particularly in coal mine areas. By 2003, land subsidence attributed to mining production and groundwater pumping with a cumulative subsidence larger than $200 \mathrm{~mm}$ affected an area of more than $79000 \mathrm{~km}^{2}$ (Xue et al., 2005; Wu et al., 2008; Zhang et al., 2014) in mainland China. The subsidence damaged mine, building and mining infrastructure,caused the deaths of many miners, and damaged the affected lands and their their land uses. In these affected areas, agricultural production and industry had to be curtailed, and a large number of the native inhabitants became homeless and had to move from the subsidence regions. Thus, the land subsidence in mined-out regions caused vast economic losses and posed great risks for local social, agricultural and industrial developments. Since 2000, the China government has implemented a national project to real-time monitor and assess the hazard and risk of the mined-out regions, and the core of this project is land subsidence risk assessment and prevention. After 15 years, the project has made great progress. Highly effective methods to mitigate subsidence have been implemented in the main coal producing regions, although the project plan has not completely solved these problems.

Many specialists have done a lot of research on the land subsidence mechanism and how to estimate the subsidence effects and asses the safety of structures built on the sinking areas. In the beginning of 19th century, the vertical-line theory (VLT) and Gnoto-normal line theory (GNLT) had been used to calculate land subsidence induced by minning in Belgium (Klatesch, 1983), VLT and GNLT proposed the equation to calculate the subsidence: $w=m \cos \alpha$, here, $w$ is the subsidence, $m$ is the thickness of mine strata, and $\alpha$ is the dip angle of mine strata. In the middle of the 19th century, many more theories were developed to predict land subsidence and explore its mechanism, such as bisector theory (Jlcinsky, 1876-1884), round arch theory (Fayol, 1885), strip-belt zone theory (House, 1897), cantilever beam theory (Halbnam, 1903), and influence line theory (Schimizx, 1932), among others (Liu, 1965). Many scholars have studied how land subsidence affects the safety of mining engineering, and a number of scientific publications on subsidence emanating from European countries and proposed several alternative methods (Tugrul et al., 2013). In the 1970s, Jones and Spencer (1977) discussed how mining subsidence damged highway structure in USA. Since the 1950s, Chi- 


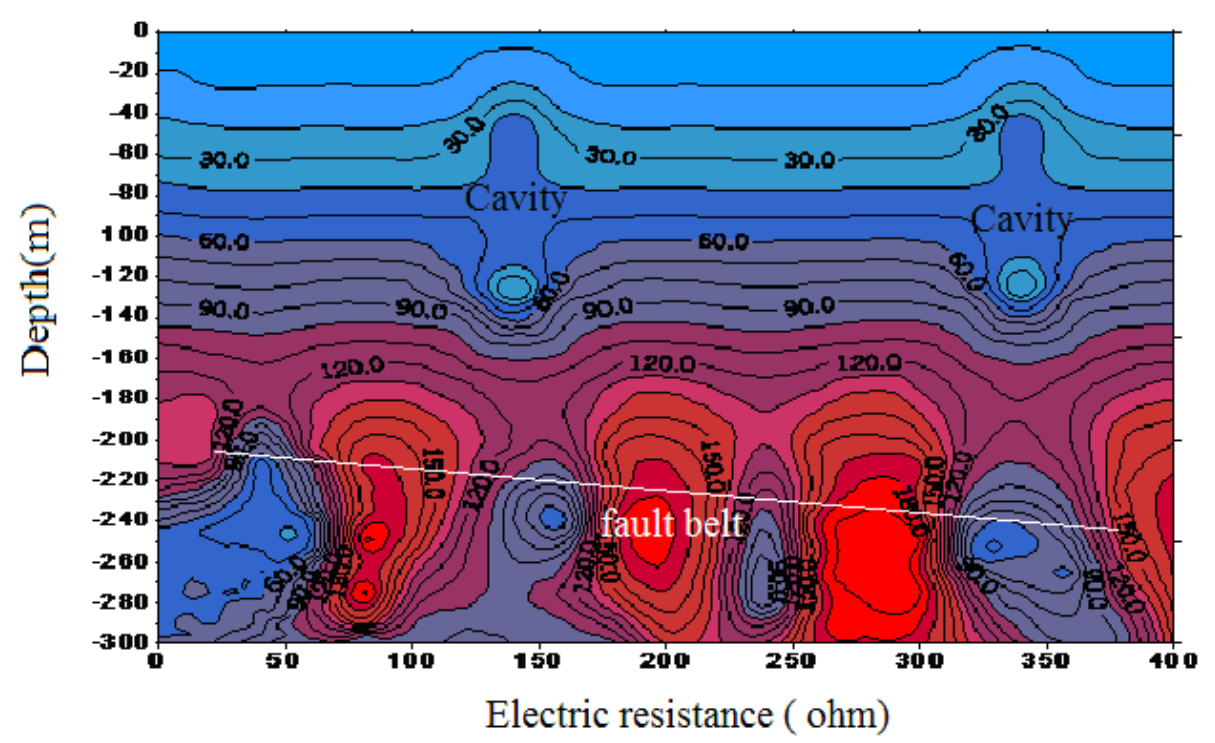

Figure 1. Electromagnetic exploring for cavity identification.

nese scholars have studied the land subsidence mechanism and protective methods, and many new theories and practical engineering measures have been referred $(\mathrm{He}, 1992)$.

In this paper, a comprehensive risk assessment framework and investigation methods for land subsidence identification are introduced, several typical subsidence mechanisms are summarized, and some successful engineering measures to mitigate the subsidence are discussed. A GIS for land subsidence risk assessment is developed and is based on site investigations and numerical simulation of subsidence process. In this system, maps of mining intensity and risk ranks are developed.

\section{Identification and types of land subsidence in mined-out regions}

In mining regions, because land subsidence is closely related to the underground excavation, it is commonly used to explore the underground cavity. In order to discover these cavities, geophysical exploration techniques have been mostly applied, such as induced polarization electrical method, 3-D seismic exploration, magnetic and electromagnetic exploration, ground penetrating radar, light detection and ranging (LIDAR), geophysical computerized tomography, electrical prospecting, and gravity methods. Generally, all of these methods have been successfully applied in identifying mined-out cavities within less than $300 \mathrm{~m}$ depth below land surface. In China, the first three methods have been most applied. Figure 1 shows a typical result for electromagnetic exploration of cavities.

The traditional theories divide subsiding materials above the mine into three belts or zones or areas: the bending belt, the fault and cracking belt, and the collapsing belt (from the

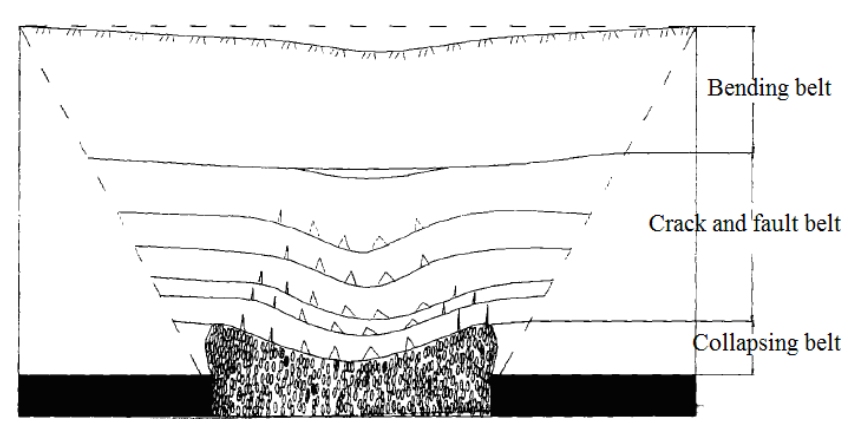

Figure 2. "Three belt" model of land subsidence types in mined-out region.

surface to the underground cavity). In the bending belt, the soil and rock are deformed but for the most parts are not mechanically failed, there are few fractures developed mainly in the vertical direction, the strata have little differential displacement and subsidence with no strata separation cracks. The thickness of the bending belt depends on the overlying rock characteristics and depth of mined-out cavity (Fig. 2). If the rock is soft and the cavity is deep, the bending deformation is more widely distributed. For the fault and crack belt, there are many cracks and faults of both horizontal and vertical directions in the rocks, and layer separation cracks are usually observed. The number and width of the rocks' cracks and faults are greater and inversely related to the distance between land surface and the cavity. In the top layer of this crack belt, the orientation of the cracks and faults is vertical toward the cavity, but in the bottom layer, the orientation is horizontal, and some strata are separated, and easily slip toward the cavity. In the collapsing belt, the rock is completely damaged, and partly or completely fill the mined-out cavities 


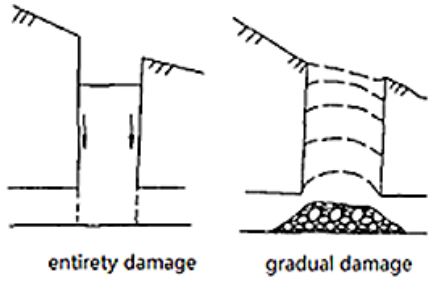

a) Arch caving collapse

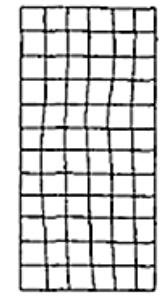

b) cantilever beam and tilting and broken cantilever beam

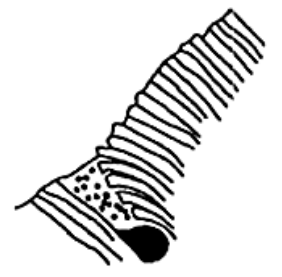

c) loose filling secondary settlement
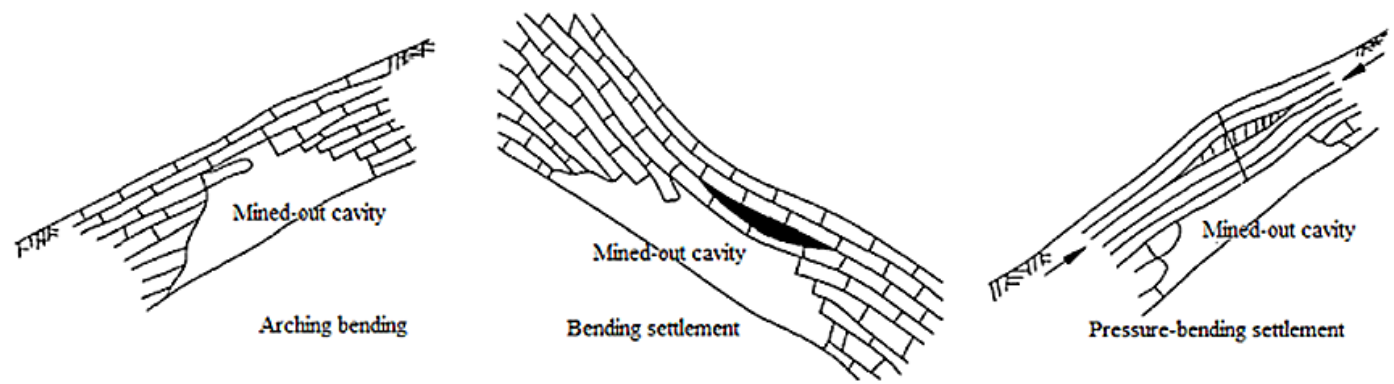

d)separated layer bending, crack and collapse

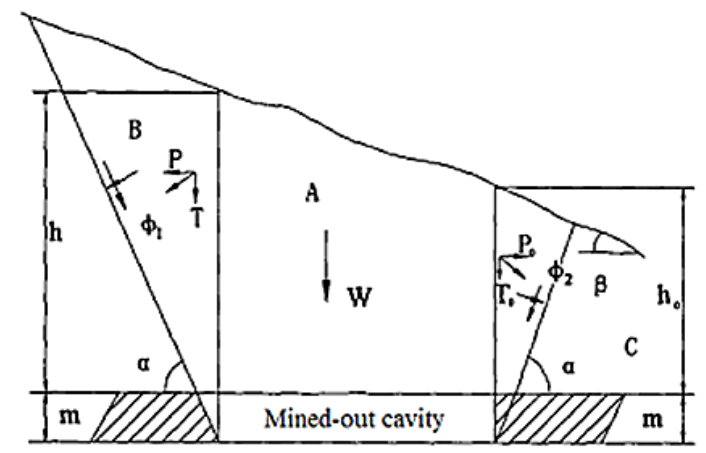

e) rock slippage

Figure 3. Land subsidence patterns in mined-out region.

depending on the rock types and thickness of mined strata. The height of the collapsing zone can be calculated as:

$h=\frac{m}{(k-1) \cos a}$,

where $h$ is the height of the collapsing zone, $m$ is the thickness of the mining stratum, $k$ is the hulking coefficient of the cracked rock (Table 1), and $\alpha$ is the inclination angle of the stratum. This traditional theory describes the rock deformation characteristics, but does not describe the land subsidence mechanism. Therefore, based on this theory alone, it is difficult or not suitable to design or plan reliable protective measures against land subsidence induced by different rock damage mechanisms. Since the 1950s, many important theories of subsidence processes in mining regions were developed by Chinese scientists, such as the rheological theory of the overburden strata in mining fields (Liu, 1995; Ran and $\mathrm{Gu}, 1998$ ), nonlinear smoothing finite element theory and large deformation theory (He and Peng, 1994; He and Zhao, 1995), probability influence function theory (He, 1992), stochastic and fuzzy model theories for land subsidence prediction (Liu, 1965; Li et al., 2010), chaotic support vector machine theory ( $\mathrm{Li}$ et al., 2008), and the thin-layer plate roof caving model theory (Zhang and Cao, 2015). According to the theoretical, numerical and in situ observations, mining-related land subsidence in China was classified into seven main types: (1) arch caving collapse (Fig. 3a), (2) cantilever beam caving of natural rock strata, including tilting and broken strata (Fig. 3b), loose filling caving secondary settlement (Fig. 3c), (4) separated layer bending, crack and 


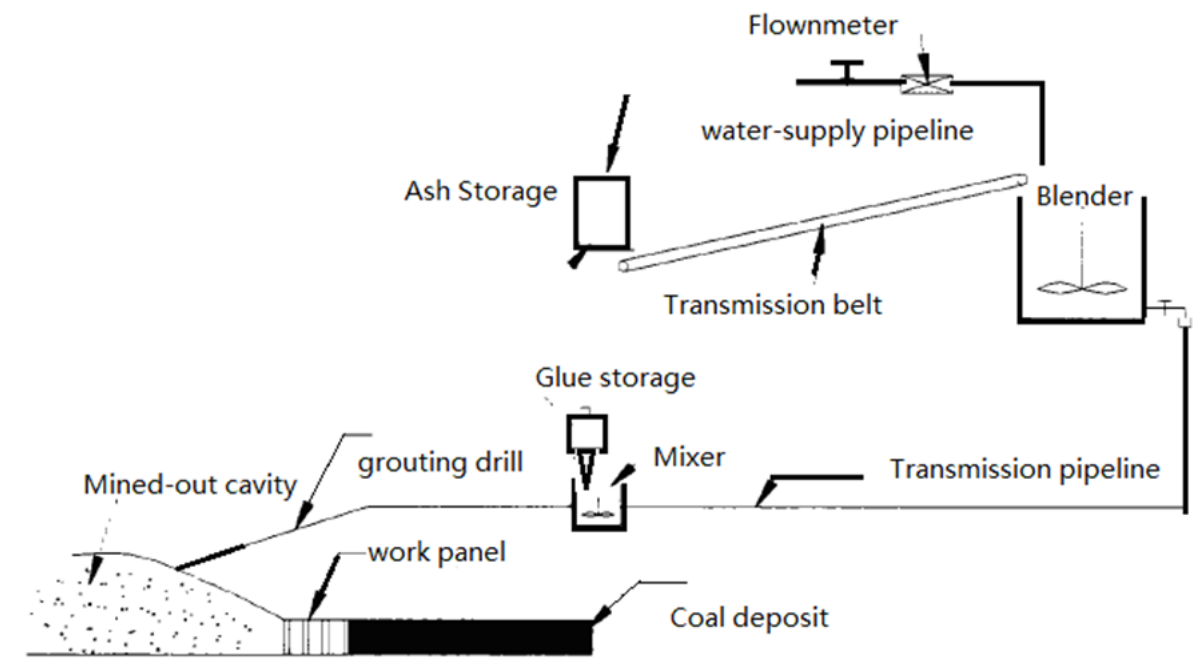

Figure 4. Simplified flowchart of a popular grouting filling method used in China.

Table 1. Hulking coefficient values of cracked rock $(k)$.

\begin{tabular}{lrr}
\hline Rock Type & $\begin{array}{r}\text { Initial crack } \\
\text { status }\end{array}$ & $\begin{array}{r}\text { Residual status } \\
\text { (compacted) }\end{array}$ \\
\hline sand & $1.05-1.15$ & $1.01-1.03$ \\
Clay & $<1.2$ & $1.03-1.07$ \\
Cracked coal & $<1.2$ & 1.05 \\
Clayed shale & 1.40 & 1.10 \\
Sandy shale & $1.60-1.80$ & $1.10-1.15$ \\
Hard sandstone & $1.50-1.80$ & \\
Soft rock & & 1.02 \\
Middle-hardness rock & & 1.025 \\
Hard rock & & 1.03 \\
\hline
\end{tabular}

collapse (Fig. 3d), (5) rock slippage (Fig. 3e), (6) rock softening and creep due to flooding and groundwater penetration, (7) collapsing due to overburden load, dynamic loads, and groundwater-level variation from natural or man-made causes (e.g. climatic variation, flooding and groundwater extraction).

\section{Main engineering treatment methods for subsidence protection}

Reclamation and protection of the areas affected by land subsidence are the important tasks for achieving sustainable development in mining regions. The Chinese government has paid much more attention to this since the 1950s, and during the recent past two decades, vast investments have been made to treat land subsidence. Based on the reclamation and protection practices, several principal engineering treatment methods have shown some success.

\subsection{Grouting filling method}

For a jointed rock mass and cavity, the grouting filling method (GFM) has been a highly effective method to control land subsidence. In our practice, the principle GFMs have included goaf-stowing with cement materials (GSC), ash grouting (AG), and low density slurry (LDS) methods. The following parameters must be considered to obtain satisfactory results with GFMs: grouting pressure, injection velocity, fluid type and density, crack density of rock mass, buried depth of cavity, volume of the collapsing belt, hydrology, construction technique and equipment. The most popular GFM in China is illustrated in Fig. 4. Here, the main filling material is ash from a power plant. The glue is a mixture of aluminium-alumine, inorganic materials and additives. Its relative density is 3.0 and its density is $1.2 \mathrm{t} \mathrm{m}^{-3}$, and it has a volumetric water content of $90 \%$. After mixing with water, the glue mixture can have a bearing capacity of $0.5-1.0 \mathrm{MPa}$ in one hour. Typically, the mass fraction of the component of grouting materials are ash (50-70\%), glue (5\%), and water (25-45\%).

\subsection{Anchor and anti-slide pile supporting system}

If the cavity is buried at less than $100 \mathrm{~m}$ depth and is overlain by hard rock mass, the anchor supporting system (ASS) or anti-slide pile supporting system (APSS) can be used to mitigate land subsidence. However, ASS and APSS are more effective in preventing the lateral deformation of the cavity. In China, ASS and APSS are usually applied to treat the subsidence in metal (gold, iron and cobber etc.) mining regions. For ASS and APSS, the important parameters include the anchorage depths of piles and anchors, pile and anchor length and spacing, pile cross section, and ratio of height and width, and stability and strength of the supporting systems. From 1995, new ASS and APSS technique have been 


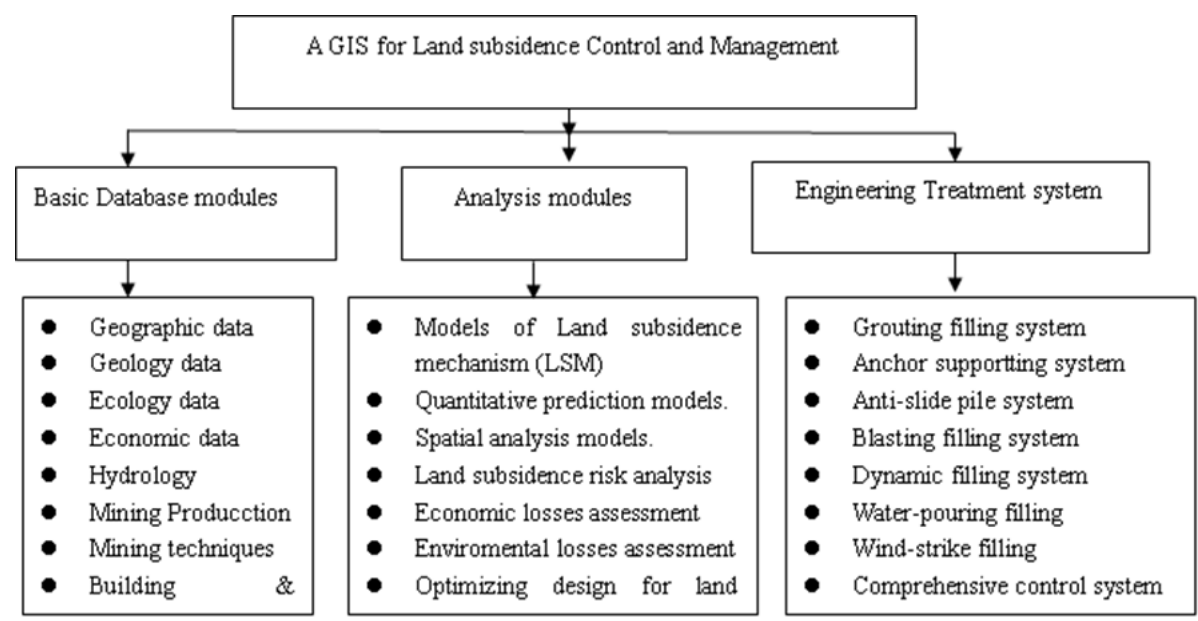

Figure 5. A GIS focussed land subsidence management system for in mined-out regions.

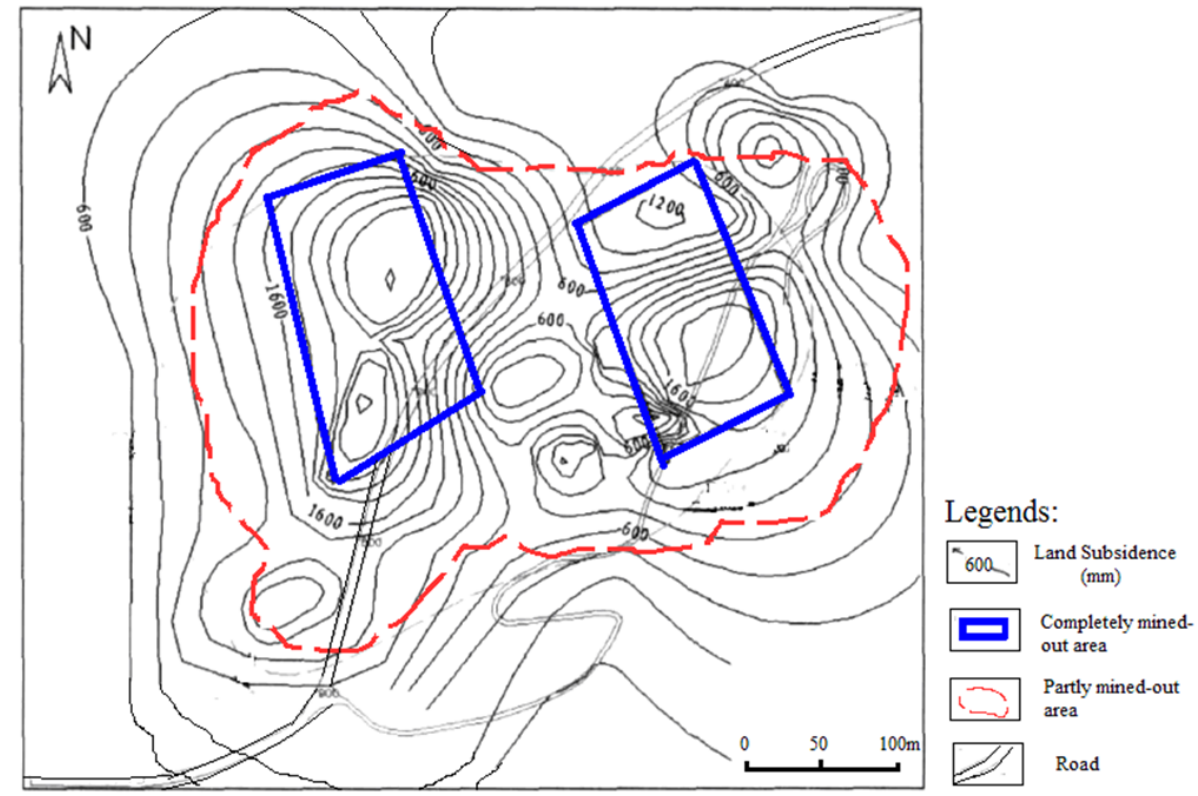

Figure 6. One of the typical maps of mining intensity and risk ranks based on GIS.

continually applied in coal mining regions, like Heilongiiang province, Shanxi province, Inner-Mongolia province and Anhui province.

\subsection{Comprehensive treatment method}

Dynamic compaction, blasting and filling, water-pouring filling (WPF) and wind-strike filling methods are used to control the subsidence in mined-out regions in China. For a large and deep subsidence area with little population, the blasting and filling method is often used, and is capable of rapidly controlling subsidence for relatively short durations. Where acceptable environmental conditions permit, the reclaimed land use is typically recreation and agriculture. Dynamic com- paction is applied to treat the shallow land subsidence, particular surface-based transportation system. WPF is often applied to prevent the deep mined-out cavity from subsiding, in those cases, it is necessary where there is rich and easily extracted groundwater. However, subsidence control with WPF method often takes a long time before it is optimally effective due to long-term creep deformation and softening with soil-rock-water interaction. Wind-strike-filling is also used to treat shallow mined-out cavities where fine sand and clay are easily available. 


\section{A GIS for land subsidence management in mined-out regions}

Managing land subsidence in mined-out regions is a complex. It entails multi-disciplinary knowledge of the geology, hydrology, geography, ecology, soil and rock mechanics, engineering, management, and risk assessment. A powerful data management and spatial analysis platform, GIS has been applied as a development tool for land subsidence management systems in China since 2000. Presently, almost all of land subsidence management systems for mining areas are based on GIS. The general management framework, flowchart and function for these systems are described in Fig. 5. One of the typical maps of mining intensity and risk ranks based on GIS is illustrated in Fig. 6. For a GIS system based on land subsidence risk assessment, prediction and prevention, these sub-systems are often at least included inside them: (1) subsidence mechanism analysis system; (2) subsidence risk assessment,mitigation and warning system; (3) subsidence spatial distribution estimation system; (4) engineering techniques to controlling and treatment system; (5) daily management system; and (6) emergency response system.

\section{Summary and conclusions}

Land subsidence in mining regions is an important manmad hazard in China and throughout the world that poses large risks for land use and environmental protection. Despite the successful application of engineering treatment methods based in part on traditional theories of subsidence processes related to underground mining, more research on subsidence processes in mined-out regions is needed particularly with respect to application of modern monitoring techniques, and the development of numerical simulation and computational methods based on refined process models. As the result of new advance in mining engineering and the growing demand for energy and mineral products, mining depths will increase. Land subsidence induced by underground mining will face new challenges, related to the increased mining depths and the potential reactivation of previously treated land subsidence. Therefore, reliable new methodologies to forecast and prevent land subsidence, for example by reducing the disturbing effect on the rock mass, must be developed. Additionally, laws and ordinances related to restricting subsidence induced by mining must been made and strictly executed, otherwise, it is possible that land subsidence risk will rapidly increase for the need to high-speed economic development of China.

\section{References}

He, G.: Mining Land subsidence, China University of Mining and Technology Press, 1992.

He, M. and Peng, T.: The problem of large deformation in softrock engineering and practical analysis of floor-heaving, J. China Univ. Mining Technol., 4, 86-91, 1994.

He, M. and Zhao, J.: Mining theory and practice under building, China University of Mining and Technology Press, 1995.

Jones, C. J and Spencer, W. J.: The implication of mining subsidence for modem highway structure, UK, Wales: Proceedings of Large Ground Tunnel Movement and Structure, University of Wales, Cardiff, UK, Halstead Press, New York, 515-526, 1977.

Karmis, M., Agioutantis, Z., and Jarosz, A.: Subsidence prediction techniques in the United States: a state-of-the-art review, Min. Res. Eng., 3, 197-210, 1990.

Klatesch, H.: Mining subsidence engineering, Springer Verlag Press, Berlin, Germany, 1983.

Li, W. X., Liu, L., and Dai, L. F.: Fuzzy probability measure (FPM) based non-symmetric membership function: engineering examples of ground subsidence due to underground mining, Eng. Appl. Artif. Intel., 23, 420-431, 2010.

Li, W. X., Gao, C. Y., Yin, X., Li, J.-F., Qi, D.-L., and Ren, J.C.: A visco-elastic theoretical model for analysis of dynamic ground subsidence due to deep underground mining, Appl. Math. Model., 39, 5495-5506, doi:10.1016/j.apm.2015.01.003, 2015.

Li, X., Wang, Q., Yao, J., and Zhao, G.: Chaotic time series prediction for surrounding rock's deformation of deep mine lanes in soft rock, J. Centre South University of Technology, 15, 224229,2008.

Liu, B. C.: The basic laws of land surface movement in coal mining, China Industry Press, Beijing, China, 1965.

Liu, T.: Influence of mining activities on mine rockmass and control engineering, J. China Coal Soc., 20, 1-5, 1995.

Ran, Q. and Gu, X.: A coupled model for land subsidence computation with consideration of rheological property, Chinese J. Geol. Hazard Control, 9, 99-103, 1998.

Tugrul, U., Hakan, A., and Ozgur, Y.: An integrated approach for the prediction of subsidence for coal mining basins, Eng. Geol., 166, 186-203, 2013.

Wu, J. C., Shi, X. Q., Xue, Y. Q., Zhang, Y., Wei, Z. X., and Yu, J.: The development and control of the land subsidence in the Yangtze Delta China, Environ. Geol., 55, 1725-1735, 2008.

Xue, Y., Zhang, Y., Ye, S. J., Wu, J., and Li, Q.: Land subsidence in China, Environ. Geol., 48, 713-720, 2005.

Zhang, B. and Cao, Sh.: Study on first caving fracture mechanism of overlying roof rock in steep thick coal seam, Int. J. Mining Sci. Technol., 25, 133-138, 2015.

Zhang, Y. Q., Gong, H. L., Gu, Z. Q., Wang, R., Li, X. J., and Zhao, W.: Characterization of land subsidence induced by groundwater withdrawals in the plain of Beijing city, China, Hydrogeology, 22, 397-409, 2014. 